\title{
A dialética da malandragem no fenótipo da moral do brasileiro.
}

(The dialectic of trickery in the Brazilian moral phenotype.)

\author{
Elson Glücksberg \\ Escola Valter Kunze Prof. Dr. Coordenador do Ensino Fundamental Sinop/MT- Brasil.
}

Fecha recepción: 01-05-2018

Páginas 96-108

Fecha aceptación: 30-06-2018

\section{Resumo.}

Este Artigo tem por objetivo demarcar as concepções sobre os conceitos da "dialética" da malandragem e do jeitinho, enquanto fenótipo cultural que fornece os parâmetros da moral do homem brasileiro, a partir de um olhar crítico-literário demarcado por diferentes autores e, em segundo momento através do confronto da teoria para com aquilo que apontaram as concepções de educadores, do ensino fundamental, em dados empíricos de campo. A metodologia para alcance dos dados, baseou-se inicialmente no levantamento bibliográfico e, em segundo momento, sobre dados quantificáveis em comunidade escolar da comunidade de Sinop, norte do Estado de Mato Grosso - Brasil. Os resultados de campo apontam para o homem brasileiro que faz da ética na vida pública e social, sua "Dialética da Malandragem, enquanto modelo (fenótipo) de sua moral relacional e de postura".

Palavras-chave: Dialética; malandragem; jeitinho; moral; bom malandro

\begin{abstract}
.
This article aims to demarcate the conceptions about the "dialectic" of trickery and little way, as a cultural phenotype that provides the parameters of Brazilian man's morality', from a critical-literary perspective demarcated by different authors and, secondly moment through the confrontation of theory with what pointed the conceptions of educators, of elementary education, in empirical field data. The methodology for reaching the data was based initially on the bibliographical survey and, secondly, on quantifiable data in the school community of the Sinop community, north of the State of Mato Grosso - Brazil. The field results point to the Brazilian man who makes ethics in public and social life his "Dialectic of 'Malandragem', as a model (phenotype) of his relational and posture morality".
\end{abstract}

Key words: dialetic; trickery; little way; morality; good crap 


\section{1.-Introdução.}

Nas concepções de Luciano Figueiredo, em obras de História, a cultura brasileira, desde a sua concepção de brasilidade (1532) vem permeada e carregada com a malandragem do "novo homem ultramarino" que, em meio às exuberantes paisagens tropicais, constituindo-se um ser com plena e total liberdade tropicalista e, dele não se exigindo plantar ou investir - somente cuidar e colher e barganhar.

Com base nas concepções deste historiador, propomos compreender as consequências que hoje resultam dessa liberdade do homem português expatriado para o Brasil, que logo cedo resultou em relação de libertinagem materializado no "jeitinho de brasileiro"; uma espécie de contracultura de sua origem e, anos depois, na contramão dos princípios jesuíticos do tomismo-cristão, que postula a boa conduta, o empenho ao trabalho e, aos valores historicistas. Ao ultramarino, as benesses que a vida tropical oferecia nas primeiras décadas; mesmo em meio à selva inóspita, nada obstante uma 'visão do paraíso' Holanda (2010), habitado por ameríndios (e ameríndias), à este português (aventureiro), favorecia manter-lhe os gêneros de primeira necessidade e vivendas, trambicado com os índios.

Aqui refere-se Antonio Candido (2010), ao relatar o português que fora trazido para 0 Brasil durante os trinta e dois anos que precederam a efetiva ocupação portuguesa. Cândido afirma que: "[...] à este primeiro bastava criar bases relacionais e se improvisar para manter sua integridade física, em meio aos índios e índias, no enfrentamento das agruras da selva, onde os únicos riscos representavam os insetos e a selva". Em meio aos benefícios, apesar da distância da Corte, o portuga expropriado pode manter-se em moral elevada perante os índios e, com eles "concubinando" em nova relação familiar, tirando proveito na coleta de gêneros; no vagar pela selva e, acima de tudo na apreciação pela dádiva da natureza, onde nada precisava ser plantado ou construído, simplesmente usado e extraído. Assim 0 autóctone 'malandro da côrte' pôde se "amalandrar", quando, desde os tempos coloniais até os dias de hoje, os benefícios à sobrevivência da generosa terra brasileira contribuíram e ainda contribuem para a construção da vida social com expressiva ociosidade. Ainda hoje dando sentido àqueles que, em sua origem já não se prestavam ao empenho pelo labor, a possibilidade ao extrativismo de subsistência.

A partir de então, várias gerações se passaram, porém o fenótipo cultural do português tropicalizado se manteve quase que autóctone, perpetuando a expressão malandreada e, bem delineada ao sol das lindas praias, com sua expressão do jeitinho padrinhesco e apadrinhador do 'bom malandro da velha côrte'.

Assim, na proposta que busca responder "os motivos da malandragem na moral dos brasileiros", nada obstante que o melhor caminho fosse buscar fundamentos epistemológicos na Dialética, na Malandragem e no Jeitinho, enquanto moral do homem brasileiro, a partir de velhos estóicos: Heráclito de Éfeso (535-475 a.C.); 
Zenão de Eleia (490-430 a.C.). Filósofos alemães: Immanuel Kant (1724-1804); Georg Wilhelm Friedrich Hegel (1770-1831) e Friedrich Nietzsche, (1844-1900).

$\mathrm{Na}$ base teórica que fundamenta este objeto, propomos um olhar na base dos escritos de alguns autores brasileiros, como: Manoel Antonio de Almeida; Darcy Ribeiro; Sergio Buarque de Holanda, além de outros acadêmicos mais recentes, quando é nos atuais que encontramos latente a discussão sobre a "Dialética da malandragem na concepção moral da cultura brasileira".

\section{2.-Fundamento Teórico.}

A base teórica que vem fundamentar, aclarar ou materializar este breve ensaio, com três variantes bem demarcadas, a saber: a) O que significa 'Dialética', em sua etimologia, à luz da filosofia Perene; b) $\mathrm{O}$ aporte e fundamento teórico sobre a 'Malandragem', enquanto contracultura de um processo ético em disposição da verdade; c) A concepção sobre o 'Fenótipo da Moral do brasileiro', enquanto base que postula sua vida em sociedade e, sua maneira malandra de ser.

\section{1.-Da Dialética.}

A história ostra que a origem da concepção sobre "dialética" vem da cultura grega quando "zenão de Eleia (490-430 a. C) é considerado o fundador da dialética". Para Aristóteles, a dialética passa a ser a concepção lógica daquilo que passa a ser provável, ao contrário de um processo racional (metafísico) que não pode ser demonstrado. Hegel também considerava Heráclito de Éfeso (535-475), o mais famoso pensador dialético. "[...] os seres não têm estabilidade alguma, estão em constante movimento, modificando-se [...] um homem não banho duas vezes no mesmo rio, porque nem o homem, nem o rio serão os mesmos".

Na base do Devir (vir a ser), Heráclito fornece a "doutrina dos contrários", resumido na "estética de Devir da realidade", quando e tese e a antítese (ser e não ser) são "[...] uma síntese contraditória e permanente da realidade" que, "só assim pode vir a ser, através dos seus dois aspectos existenciais, ou: "(no mesmo rio, entramos e não entramos)". Kant (1724-1804), definindo essa questão com inspiração em Heráclito, quando passa a definir a dialética "[...] como a 'lógica da aparência'. Para ele, a dialética é uma ilusão, pois baseia-se em princípios que são subjetivos.

Para Hegel (1770-1831) a Dialética constitui-se em: "[...] três momentos, chamados: tese (em nosso exemplo, a revolução), antítese (o terror subsequente) e síntese (o estado constitucional de cidadãos livres)". A partir destes dados verificamos as propostas de Nietzsche quando discute a questão da Dialética na teoria do "Novo Homem". A partir destes dados e, com um olhar para dentro da cultura brasileira, foi possível verificar que, o povo brasileiro, desde a sua concepção ibero-espanhola (Séc. XV) até os dias de hoje, tem-se influenciado pela cultura tomista católica (do novo homem), com educação e catequese Jesuíta que perdurou até sua expulsão em (1759). Teve formação com valores do tomismo-cristão, com estreito vínculo à filosofia cristã. 
Por consequência, a concepção social para a boa conduta relacional carrega 0 Fenótipo da moral social cristã, consubstanciada na doutrinada dos Jesuítas (em sete Povos da Missões), de cuja reminiscência didático-pedagógica, até os dias de hoje se faz sentir na concepção relacional ou postura social de cada brasileiro. Porém, a forma do 'jeitinho' e da 'malandragem' tem outros fatores patológicos.

0 resultado desse sincretismo resulta na justificativa do Jeitinho, da Malandragem que se alimentou da doutrinação jesuítica gerando aquilo que podemos chamar de "Dialética Social cristã" que se materializa nos Partidos Políticos que nada mais significam do que o reflexo das pastorais da 'esquerda religiosa', representando nas mais diferentes regiões brasileiras. Nessa partidarismo de esquerda fica notória a "Dialética do Socialismo cristão", nada obstante se assemelha à disposição do homem brasileiro, com sua jinga e malandragem que materializa a Dialética do Materialismo Histórico de Karl Marx. Desta forma, a forte concepção fenotípica do brasileiro, dá sentido à concepção do "Socialismo cristão", retroalimentando-se da pedagogia Libertadora, enquanto proposta vinda da "Teologia da Libertação de Paulo Freire", voltada à classe trabalhadora, em especial dos campesinos.

\section{2.-Da malandragem.}

$\mathrm{Na}$ etimologia da Malandragem do homem brasileiro, algumas concepções devem ser vistas à luz do Tomismo Cristão, quando a 'ilicitude' sobre determinada relação demanda parâmetros estoico-cristãos, na determinante da improbidade relacional ou de postura, passando a ser considerada malandragem. Neste caso, utilizar-se de malandragem para não trabalhar, caracteriza a engenhosidade e sutileza, que se opõem à lógica, do trabalho e da honestidade, uma vez que a malandragem pressupõe que o labor não favorece e, traz sacrifícios. Porém, aquele que pratica a malandragem (o malandro) age no fenótipo do adágio Brasileiro, traduzido e expressado com o nome de: Lei do Gerson, ou: "o gosto de levar vantagem em tudo".

Também Diniz, afirma que: a cultura da malandragem surgiu nos tempos da colonização, quando a Coroa Portuguesa, com medo de perder o seu domínio e, não pudesse explorar as riquezas brasileiras, decidiu povoar o território, enviando para cá (o Brasil), a escória de Portugal, [...] ladrões, bandidos, presos condenados, assassinos, prostitutas e, toda espécie de renegados. Considerando a linha de investigação antropo-racial, também Rodrigo Cavalcante vem propor um olhar sobre a "multirracialidade brasileira" que tem forte influência sobre a concepção do malandro brasileiro, buscando saber; "[...] de onde vem a malandragem brasileira?". Cavalcante, na Revista Super Interessante (Ed. 31/10/2016), registra que: "somos 0 produto da miscigenação entre os colonizadores portugueses, os índios que aqui viviam e os africanos trazidos como mão-de-obra escrava". Assim o autor ainda fala que "[...] somos um povo mestiço, genética e culturalmente".

Agora mais oportuno, costuma-se apontar a corrupção como uma das maiores mazelas da sociedade brasileira. Quando questionada acerca desse assunto, a opinião pública tem como alvo favorito criticar a classe política. No entanto Cavalcante conclui que "a concepção do brasileiro se funde e volatiliza". Em referência ao jeitinho 
brasileiro, à malandragem e ao jogo de cintura, "categorias" que, já incorporadas à cultura brasileira, convivem lado a lado com os valores ético-morais mais tradicionais." Holanda em, 'Raízes do Brasil', dá concepções mais detalhadas sobre a origem do "jeitinho brasileiro" e da "malandragem do homem brasileiro", concluindo que "[...] a propensão para a sobreposição dos laços familiares à estrutura e exigência do Estado são, de fato, grandes, Uma vez que, desrespeitam-se as leis e resoluções estatutárias e, buscam-se os conceitos padrinhescos do -"você sabe com quem está falando?"; (Holanda, 1995, p. 39). Sobre este enfoque, Diniz (2018) também apresenta um quadro bastante sofrível quando comenta que: "[...] atualmente, encontrar um cidadão honesto e de caráter, no Brasil, é mesma coisa que encontrar uma agulha no palheiro." Holanda (ib.id.) também destaca as três primeiras décadas de cultura brasileira, onde: "[...] o Brasil era visto com certo desleixo e abandono". (Holanda, 1995, p. 43). Para este pesquisador, este fator se dava devido ao fracasso do comércio da 'Cia. dá Índias', quando em fins do século XIV e início do séc. XV, a Coroa Portuguesa já não via mais grandes vantagens em manter ativa sua rota para o Brasil.

Essa postura dos pioneiros vem retratado em Holanda, com sua "Visão do Paraíso (2010)", quando destaca o 'mito da origem' que moldou o caráter do homem brasileiro. Para Holanda, o fetiche se instaurou pela 'não necessidade ao trabalho', (referindo-se ao plantio e ao labor do investimento telúrico). Ao homem brasileiro competia apenas colher o que a natureza generosamente lhe fornecia ou somente "malandrar-se" para com os índios, solicitando seus préstimos e, até barganhando com eles seus víveres. No paradoxo dessa postura, e, se concebido, o que apontam diretrizes sobre o pecado hebraico, (livro de Gênesis), destaca o necessário "empenho ao trabalho", como forma de redenção de eventual dolo no Paraíso. Para 0 homem brasileiro, nada obstante que esteja distante desse estigma, quando passou a mitificar o trabalho, onde sua "boa vida" representava o papel de Adão (bíblico) no paraíso, sem a devida necessidade ao trabalho.

Com base nessa etimologia, com olhar para dentro daquilo que concebem alguns pesquisadores brasileiros, verificamos que, para alguns o malandro se origina por fatores que vão, desde a mistura das três raças, até fatores de ordem climática (tropicalismo), até mesmo de ordem libidinosa no concubinato com os índios que forneciam (em troca de bugigangas) os gêneros alimentícios extraídos na natureza. Ainda outros fatores podem ser consubstanciados, à exemplo da cultura pirata caribenha, centrada na expropriação e no roubo. Ainda há outros autores que dão ênfase à condição de falta de caráter dos primeiros que aqui chegaram, quando em seu melhor currículo figura expatriados, feito escória degredada da Europa. Neste caso diz DaMatta [...] o herói deve sempre ser um pouco trágico para ser interessante, com sua vida sendo definida por meio de uma trajetória tortuosa, cheia de peripécias e desmascaramentos. (DaMatta, 1997, p. 257).

DaMata também vê a concepção da ambiguidade destacada nas concepções de Antonio Cândido (op. cit.) quando o brasileiro livre, do período do Brasil Colônia, não se sentia empregado e, portanto nada comprometido com a sociedade, restando-lhe 0 ócio e a malandragem da negociata para sobreviver. Neste sentido DaMatta, referindo-se ao malandro, vem afirmar que: "[...] é um personagem deslocado, pois não cabe nem dentro da ordem, nem fora dela: vive nos seus interstícios, entre a 
ordem e a desordem, utilizando ambas e nutrindo-se tanto dos que estão fora quanto dos que estão dentro do mundo quadrado da estrutura" (DaMatta, 1997, p. 172) Percebe-se então, que 0 brasileiro livre, desde a concepção das Capitanias Hereditárias, até a chegada da Família Real (1808) carregava a malandragem como forma e identidade relacional, uma vez que, nem a classe dominante, nem a figura de escravizado the favoreciam, passando a eleger-se dentro de um perfil estabelecia a desordem, ou sua própria ordem, dentro de um estado de ordem regimental. Se na concepção estoico-tomista-cristã, fica claro que: "no suor do teu rosto comerás o teu pão, até que voltes à terra [...] (Gênesis 3:19), a busca pela ocupação e pelo labor são as concepções da ordem e do bem estar. Porém, para o malandro brasileiro, (homem livre do Brasil Colônia) não representava uma concepção de sentido racional. Nem tão pouco a cultura lhe exigia que sua postura fosse concernente à visão do trabalho.

Assim, a forma e figura do bom malandro deixou como herança ao homem brasileiro as múltiplas faces do discurso social, com sua singular fama no gingado e bem astuto em habilidade de tirar vantagens em todas as relações. Este malandro de hoje se engendrou na relação e interlocução com o Senhor de engenho, com o Escravo, nos bastidores da política e no comércio, desde o Brasil Colonial. Para Lima (Dissertação de Mestrado-UnB/2017) evidencia a vida e postura de um 'bom malandro', quando conclui que: "Geralmente estes não têm bens de raiz, nem família, nem seguem às leis, pois estes fatores os prenderiam à ordem e os condenariam a viver nela. Eles, portanto, vivem sós, em um ambiente penoso, tendo somente a si próprios como suporte de sobrevivência, tirando proveito de certas situações, convertendo todas as desvantagens em vantagens. Este também é excluído do mercado de trabalho ou é simplesmente avesso a tal prática". (Lima, 2017. p. 40).

Silva Lima (op. cit.) ainda considera que "o malandro não deseja corrigir o mundo, quando não almeja modificar o que considera injusto no sistema social, político e/ou econômico no qual está inserido (p. 41)." Para tanto sua postura de sagaz e esperto Ihe favorecem para enganar outros, aplicando pequenos golpes, não se preocupando com as consequência de seus atos. Para Diniz (op. Cit. 2018):

[...] os cidadãos que se recusam ao 'jeitinho' são considerados tolos pela sociedade, pois, ser honesto num país de corruptos é mesma coisa que nada. [...] empresário golpista é considerado cidadão emérito; [...] pagar propina a funcionários públicos a políticos, por empresas privadas em troca de benefícios milionários, decorrentes da fraude em licitações [...] passou a ser uma conformidade dos procedimentos jurídicos e regimentais. Também Cavalcante (2016), retomando as concepções de Schwarcz, diz que: [...] o advento do malandro está vinculado à questão racial no país. 0 malandro seria a figura do mulato brasileiro que dribla o preconceito e consegue uma certa ascensão social por meio de favores conquistados com ginga e simpatia. Schwarz (2000, p. 16) vem afirmar que: "Nem proprietários nem proletários, seu acesso à vida social e a seus bens depende materialmente do favor, indireto ou direto de um grande. O agregado é a sua caricatura. O favor é, portanto, 0 mecanismo através do qual se reproduz uma das grandes classes da sociedade, envolvendo também a dos que têm."

Diniz (op. cit. 2018) conclui que: "o personagem do 'Zé Carioca', proposto pela empresa americana Walt Disney, vem apresentar a figura do 'bom malandro 
brasileiro', quando vem materializar o 'por quê' que "[...] o Brasil ocupa os piores lugares nos ranques mundiais [...]". Já o antropólogo Gilberto Freire (em Casa Grande e Senzala - 1933) onde deixa claro que, todos os brasileiros, desde o mais alvos até os mais mulatos trazem em seu genótipo as pintas do negro e do índio. Renato da Silva Queiroz, contribui afirmando que: "a cultura brasileira é permeada por uma ambiguidade ética que, em termos de 'honesto', 'corrupto', 'esperto', 'otário', 'malandro', se misturam num confuso caldeirão moral".

\section{3.-Breve contexto.}

Na década de 1970 o literato Antônio Candido publicou "Dialética da malandragem". Esta obra tornou-se referência obrigatória para quem busca compreender o tema da malandragem presente no fenótipo social do homem brasileiro. Também na obra "Memórias de um Sargento de Milícias", (1854), Manoel Antonio de Almeida - (18311861), destaca Leonardo Pataca Filho, na condição do grande malandro da literatura brasileira. Estes autores trazem à baila um velho e, ao mesmo tempo atual dilema: "a falta de ética na política e, na vida relacional do homem brasileiro, em seu dia-adia". Levando em consideração que, desde os tempos coloniais até nossos dias, pouco tem mudado na postura moral de expressivo número de brasileiros; salvo a readequação da malandragem e do jeitinho.

Considerando aspectos de ordem relacional e moral, Pinheiro (2017), conclui que: "A Ética é a ciência da moral. É ela quem sinaliza o desenvolvimento histórico e cultural da humanidade. Ao longo da história, a evolução da ética é determinada pela mudança dos valores morais e por leis de cada época". Portanto e, para entender o que vive e pensa o homem brasileiro com sua representação do jeitinho da malandragem, temos a considerar sua representação de atitudes, quando atos de desonestidade fazem de sua postura sua maior identidade, onde quase que todos os dias surgem expressões expugnáveis e de repúdio com apelo à ética. Dando maior clareza sobre esta concepção, o colunista Antonio Dirceu Pinheiro, do Jornal Datafolha afirma que, em recente pesquisa encomendada pelo Instituto Brasileiro de Ética Concorrencial (ETCO): "[...] 90\% dos jovens pesquisados, na faixa etária entre 14 e 24 anos, afirmaram que a sociedade brasileira é pouco ou nada ética. Para $57 \%$ dos entrevistados os próprios familiares foram considerados pouco ou nada éticos. Quando perguntados à eles próprios se são éticos, $63 \%$ se consideram relativamente éticos e, apenas $8 \%$ deles se consideram éticos o tempo todo".

Nada obstante os levantamentos do Jornal Datafolha (op. cit.), este já nos oferece robusta informaçã̃o para antecipar boa leitura sobre a realidade moral dos brasileiros. Se considerada apenas a última pergunta que busca saber sobre 'o nível de ética dos informantes'; destes, apenas $8 \%$ se consideram éticos o tempo todo. Logo e, por lógica 92\% não adotam posturas éticas o tempo todo, restando-lhes a postura mural duvidosa, que macula o processo da permanência na verdade e na honestidade.

\section{3.-Metodologia.}

Os dados da investigação desenhou-se em bases bibliográficas, históricas e literárias a partir de escritores clássicos, e brasileiros. Os dados de campo, a partir dos foram alcançados junto à 60 (sessenta) professores do ensino fundamental da rede 
municipal de Sinop/MT, com a estrutura de ficha/perguntas de dados quantificáveis, para 0 alcance quantitativo. Assim, desenhou-se um modelo e perfil "misto" com base nas propostas do metodologista Sampieri (et.al. 2006, p. 18): "Nos estudos que englobam os dois enfoques da pesquisa (enfoques bimodais: de duas etapas, bimodais ou mistos) [...] exige um domínio completo sobre ambos os enfoques e uma mentalidade aberta. Agrega complexidade ao projeto de estudo, mas contempla todas as vantagens de cada um dos enfoques. A Pesquisa oscila entre os esquemas do pensamento indutivo e dedutivo, além de exigir um forte dinamismo por parte do pesquisador durante o processo".

Dessa forma, demarcamos dois perfis 'quali-quantitativo', onde o marco bibliográfico, em aporte "qualitativo"; em confronto aos dados de campo, com perfil "quantitativo".

\section{4.-Discussão dos resultados.}

Em dados de campo, para alcançar olhares sobre a "Dialética do Malandro no Fenótipo da Moral do Brasileiro", já na primeira pergunta propomos levantar dados com maior clareza sobre o que vem significar o "Jeitinho" na intersubjetividade que 0 homem brasileiro tem ao lançar-se em relações sociais.

\section{Informe 1:}

\begin{tabular}{|l||l|l|}
\hline $\begin{array}{l}\text { 1a- Perqunta: Considerando o Jeitinho brasileiro uma espécie } \\
\text { de }\end{array}$ & $\begin{array}{l}\text { Infor } \\
\text { me }\end{array}$ & $\%$ \\
\hline \hline $\begin{array}{l}\text { a- É consequética da Malandragem", você conclui que: } \\
\text { Brasil. }\end{array}$ & 54 & 90,00 \\
\hline \hline b- É consequência da da falta de caráter dos primeiros a ocupar o & 5 & 6,66 \\
\hline \hline $\begin{array}{l}\text { c- É consequência da cultura licenciosa do português 'bom } \\
\text { malandro da Côrte'. }\end{array}$ & 2 & 3,34 \\
\hline \hline $\begin{array}{l}\text { d- É concepção sem dados, que pode ser ajustada com } \\
\text { educação escolar. }\end{array}$ & 0 & 0,00 \\
\hline \hline TOTAL DE INFORMANTES & 60 & 100 \\
\hline
\end{tabular}

Fonte: A própria Pesquisa.

Em resultado junto aos educadores da rede municipal de Sinop/MT, 54 informantes, dentre 0 universo de 60 ou $90 \%$ (noventa por cento) apontaram tratar-se de: "consequência da falta de caráter dos primeiros a ocupar o Brasil". Fica claro que, a expressiva maioria dos formadores da educação fundamental do norte de Mato Grosso acreditam que o Jeitinho brasileiro, em forma de "Dialética da Malandragem", vem originado no caráter desenvolvido nos primeiros portugueses que vieram para ocupar as terras inóspitas do Brasil. Ou conforme destaca Diniz (op.cit.): A cultura da malandragem surgiu nos tempos da colonização, quando a Coroa Portuguesa, com medo de perder seu domínio e, não poder explorar as riquezas brasileiras, decidiu povoar o território, enviando para cá (o Brasil), a escória de Portugal, [...] incluindo 
ladrões, bandidos, presos condenados, assassinos, prostitutas e, toda espécie de renegados.

Alguns antropólogos brasileiros atribuem tal postura à mistura das raças, o fator da origem da malandragem do brasileiro. Assim acredita Darcy Ribeiro em, "Raízes do Brasil", (op, cit.). Estes dados, porém, não se confirmam nesta investigação, quando apenas 4 educadores, ou 6,66\% acreditam ser "consequência da mistura de raças, a malandragem no Brasil". Fica claro que, os educadores, conhecedores da História do Brasil, vem confirmar dados que apontam para "o português, bom malandro da Corte" que chegou às terras Tupy/guaranís, em 1500 e, nas três primeiras décadas se encarregou por traçar o perfil relacional com "Jeitinho" para sobreviver em meio às agruras da selva e, relacionar-se com grupos estranhos à seus velhos costumes.

Para a segunda variável da problemática central, onde propomos um olhar mais especificamente sobre a "Malandragem" do homem brasileiro, destacamos 0 que apontaram os educadores:

\section{Informe 2:}

\begin{tabular}{|l||l|l||}
\hline $\begin{array}{l}\text { 2}^{\mathrm{a}} \text { - Pergunta: Considerando que há forte malandragem entre os } \\
\text { brasileiros de hoje. Segundo você; isso se dá por: }\end{array}$ & $\begin{array}{l}\text { Infor } \\
\text { me }\end{array}$ & $\%$ \\
\hline \hline a- Falta de cultura ética, desde a colonização portuguesa. & 48 & 80,00 \\
\hline \hline $\begin{array}{l}\text { b- A mistura de raças produziu o egocêntrico, despreocupado } \\
\text { com o social. }\end{array}$ & 8 & 13,33 \\
\hline \hline $\begin{array}{l}\text { c- Apenas na modernidade o brasileiro é assim, devido às mídia } \\
\text { que o denunciam. }\end{array}$ & 4 & 6,67 \\
\hline \hline $\begin{array}{l}\text { d- A malandragem já não existe mais; houve avanços de ordem } \\
\text { moral. }\end{array}$ & 0 & 0,00 \\
\hline \hline TOTAL DE INFORMANTES & 60 & 100 \\
\hline
\end{tabular}

Fonte: A própria pesquisa.

Considerando a resposta que, também aqui vem destacar "os motivos pela forte malandragem entre os brasileiros de hoje", constatamos que 48 informantes - ou 80\% (oitenta por cento) apontaram para: "falta de cultura ética, desde a colonização portuguesa". Ou seja; também aqui a resposta vem dar sentido à concepção anterior, quando 'a falta de ética do homem colonizador' traz à luz aquilo que deveria ser observado em livros de história'. Ou, postos à luz daquilo que a consciência coletiva precisa saber, através de revisitação da ontologia dos valores do home $\mathrm{m}$ português na formação do homem brasileiro.

DaMata (op. cit.), considera esse homem brasileiro: "[...] um personagem deslocado, pois não cabe nem dentro da ordem, nem fora dela: vive nos seus interstícios [...]. Assim, nos interstícios que se estabelecem entre ordem e desordem, o Malandro brasileiro vem rechear os espaços da côrte de hoje. Ou: os palácios do Governo Federal, quando seu papel de lobista, (quase miliciano), vem dar a matiz e 0 tom da conversa que se estabelece em cada gabinete. Seu papel também é conhecido como 'Doleiro", quando se especializa em lavar dinheiro (sujo) das propinas e 
desmandos padrinhescos que se estabelecem entre empresas privadas e, a verba pública que se destina ao investimento em obras públicas.

Se na eminência parda de um homem que, aparentemente se mostra fugaz e cinzento está a mazela da Corrupção brasileira, nada obstante que seu papel se modernizou como "malandro da Côrte". E, o pior de tudo: um personagem próximo de muito e dos políticos que se dizem verdadeiros defensores da verdade.

Considerando a terceira variável do eixo temático, quando propomos observar alguns exemplos de ordem prática. Ao levar em consideração denúncias sobre o Governo Federal. Entendemos oportuno o que disse o presidente da ABCAM - Associação Brasileira de Caminhoneiros, ao afirmar que "o Governo Federal não Ihes atendeu acordos firmados em reuniões de classe de caminhoneiros, fator pelo qual eclodiu a maior greve de caminhoneiros (21-30/junho/2018) que o Brasil já teve até aqui.

\section{Informe 3:}

$3^{\text {a }}$ - Pergunta: Com base nas denúncias da ABCAM - Associação Brasileira de Caminhoneiros de que, o Governo Federal, por duas negociações anteriores, não cumpriu sua parte nos acordos para com os caminhoneiros do Brasil; motivo pelo qual eclodiram em paralisação por 10 dias. Segundo você, o Governo Federal não cumpriu por quê:

a- É corrupto, representando o homem brasileiro

b- Apenas malandro, sem o compromisso sério de cumprir acordos.

c- Não representa um problema. O Governo tem outras atenções para atender.

d- Não tem obrigações, visto que acordos podem ser revistos.

TOTAL DE INFORMANTES

\begin{tabular}{|l||l|}
\hline $\begin{array}{l}\text { Infor } \\
\text { me }\end{array}$ & $\%$ \\
\hline 56 & 93,33 \\
\hline 4 & 6,67 \\
\hline 0 & 0,00 \\
\hline 0 & 0,00 \\
\hline 60 & 100 \\
\hline
\end{tabular}

Fonte: A própria pesquisa.

Em resposta à questão apresentada pelos caminhoneiros e, considerando a falta de atenção dada pelo Governo Federal para com essa classe do transporte, dado pelos educadores verificamos que 56 informantes - ou 93,33\% (mais de noventa e três por cento) apontaram: "o Governo é corrupto e representa o Homem brasileiro". Estes dados coincidem com o elevado 'índice de desaprovação' que o Governo Federal vem sofrendo nos últimos dias, no Brasil. (Datafolha 28/06/2018). Sua reprovação dos brasileiros chega à $96 \%$ que 0 consideram ruim.

Na concepção de Renato da Silva Queiroz, (op. cit.), "a cultura brasileira é permeada por uma ambiguidade ética que, em termos de 'honesto', 'corrupto', 'esperto', 'otário', 'malandro', se misturam num confuso caldeirão moral". Seguramente que o Governo Federal, ao descumprir com as negociações feitas aos caminhoneiros, empurrandoos para a necessidade de 'cruzar-os-braços' e parando o Brasil, nada obsta que 
demonstrou (na fala de Queiroz), sua "ambiguidade de 'esperto e malandro"'. Assim, nada de anormal se de forma fenotípica o homem brasileiro não se empenha por cumprir com acordos firmados. Logo, nada obstante, o Governo tivesse que cumprir?!

Na quarta e última variável, um olhar sobre aquilo que representa a cultura brasileira, em termos de Ética e postura moral, com dados, levando em consideração "os que protestam, criticando a postura moral do Governo Federal e, demais políticos".

\section{Informe 4:}

\begin{tabular}{|l|l|l||}
\hline $\begin{array}{l}\text { 4- Pergunta: Com base na crítica da razão prática (Kant), 0 } \\
\text { homem brasileiro que protesta nas ruas pela corrupção na } \\
\text { política, faria diferente se chegasse ao poder? }\end{array}$ & $\begin{array}{l}\text { Infor } \\
\text { me }\end{array}$ & $\%$ \\
\hline a- Faria totalmente diferente. & 2 & 3,34 \\
\hline b- Faria parcialmente diferente. & 8 & 13,33 \\
\hline c- Apenas ficaria indiferente para a corrupção. & 12 & 20,00 \\
\hline \hline d- Seria igualmente corrupto, envolvendo outros. & 38 & 63,33 \\
\hline TOTAL DE INFORMANTES & 60 & 100 \\
\hline
\end{tabular}

Fonte: A própria pesquisa.

$\mathrm{Na}$ informação dos educadores, verificamos que 38 - ou 63,33\% acreditam que "os brasileiros que protestam, reivindicando mais ética e menos corrupção na política", fariam o mesmo visto no atual Governo Federal. Em segundo momento outros 12 ou $20.00 \%$ acreditam que os brasileiros que protesta ficariam "apenas indiferentes para com a corrupção no Governo".

Vale ressaltar que, o papel do 'bom malandro da côrte" se evidencia, quando a troca de favores, distribuição de cargos e, jeitinho padrinhesco causa certa amnésia cerebral até em quem acredita que possa ser diferente. A cultura malandra se espraia, se evidencia até mesmo nas concepções dos educadores, quando entre estes, 8 ou 13,33\% acreditam que, os que protestam contra a falta de ética na política, "fariam parcialmente diferente". Aqui evidencia aquilo que Silva Lima (op. cit.) considera: "o malandro não deseja corrigir o mundo, quando não almeja modificar o que considera injusto no sistema social, político e/ou econômico no qual está inserido".

Os educadores parece demonstrar que "o homem que protesta. Logo, também não será ele que fará diferente e, que trará mudanças". Este malandro político seria igualmente corrupto, juntamente com outros tantos, ao chegar-se ao poder. Portanto, confirma-se a cultura do 'jeitinho e da malandragem' do homem brasileiro, quando apenas 2, ou 3,34\% acreditam que: "protestadores fariam diferente ao chegar no poder". Aqui evidencia a realidade que desconsidera a capacidade de mudar, desconsidera a capacidade de haver mais ética na política e na relação social dos 
brasileiros. Triste realidade essa que desconsidera alternativas que possam trazer melhor postura ética na política e, na cultura relacional do Homem Brasileiro.

\section{4.-Conclusão.}

Considerando que "na malandragem do homem brasileiro", apesar das diferentes epistemologias apontarem para dispares olhares ontológicos, nada obstante que possamos considerar a dinâmica do jeitinho e da malandragem uma "dialética" que vem dar um sentido sinergético e dinâmico no paradoxo "Ética e falta dela", do homem brasileiro.

Se a prática da política brasileira perpassa e, até se alimenta da malandragem, quando sua melhor explicação busca evidenciar o 'bom malandro da côrte portuguesa', também nada impróprio considerar que, nas explicações de Silva Queiroz (ibid.). Esteja a melhor compreensão: "a cultura brasileira é permeada por uma ambiguidade ética que, em termos de 'honesto', 'corrupto', 'esperto', 'otário', 'malandro', se misturam num confuso caldeirão moral".

A melhor das leituras sobre as respostas dos educadores, paira num prisma nada alentador, quando também Diniz (op. cit. 2018 s. p.) vem apresentar suas concepções ao afirmar que: "[...] atualmente, encontrar um cidadão honesto e de caráter, no Brasil, é mesma coisa que encontrar uma agulha no palheiro." Aqui os dados de campo parecem apontar para essa direção e confirmar os diferentes teóricos, quando $90 \%$ dos informantes, ao considerar a 'falta de caráter ético, 0 jeitinho e a malandragem' concordam ser originários "da falta de caráter dos primeiros portugueses que ocuparam o Brasil".

Também para Silva Lima (ibid.), "o malandro não deseja corrigir o mundo, quando não almeja modificar o que considera injusto no sistema social, político e/ou econômico no qual está inserido". Neste caso, a concepção levantada junto aos educadores, leva à crer que, de fato poucos fariam diferente ao chegar aos cargos públicos. Ou seja: Em síntese, disto deduzimos que, o homem brasileiro vem fazer da ética na vida pública sua "Dialética da Malandragem, enquanto modelo (fenótipo) de sua moral social e relacional".

\section{5.-Referências.}

Candido, A. (1993). Dialética da Malandragem. (In): O discurso e a cidade. São Paulo: Duas Cidades.

Cavalcante, R.A. (2018). Cara do brasileiro. Recuperado de: https://super.abril.com.br/cultura/a-cara-do-brasileiro.

Diniz, M.F. (2018). A cultura da Malandragem no Brasil. Recuperado de: https://marisadiniznetworking.blogspot.com/2014/04/a-cultura-damalandragem-no-brasil.html. 
Revista Internacional de Apoyo a la Inclusión, Logopedia, Sociedad y Multiculturalidad. Volumen 4, Número 3, Julio 2018, ISSN: 2387-0907, Dep. Legal: J-67-2015

http://riai.jimdo.com/

DaMatta, R. (1997). Carnavais, malandros e heróis: para uma sociologia do dilema brasileiro. Rio de Janeiro: Rocco.

Freire, G. (2010). Casa Grande e Senzala. 28a ed. São Paulo: Cultura.

Holanda, S.B.de. (1995). Raízes do Brasil. 26ª ed. Rio de Janeiro: José Olympio.

Nietzsche, F. (2005). Genealogia da moral. Trad. Paulo, C.S. São Paulo: Companhia das Letras.

Pinheiro, A.D.(2018). O povo brasileiro vive uma série crise ética. Recuperado de: https://www.dm.com.br/opiniao/2017/06/o-povo-brasileiro-vive-uma-seriacrise-etica.html.

Silva, L.A.T. (2017). Do malandro ao bandido: representações de personagens periféricos em Marcos Rey e Paulo Lins. Dissertação de Mestrado. Brasília: UnB.

Schwarcz. L.M. (2018). Complexo de Zé Carioca. Notas sobre uma identidade mestiça e malandra. Recuperado de: www.anpocs.org.br/portal/publicacoes. 